\title{
Cihazların Görsel Dili: Klima Uzaktan Kumandaları Üzerindeki Grafik Semboller
}

Yrd. Doç. Demet Karapınar

\section{Özet}

Teknolojinin gelişmesine bağlı olarak, birçok elektronik cihaz gündelik yaşantımızın ayrılmaz bir parçası haline geldi ve bu cihazların neredeyse hepsinin üzerinde grafik semboller bulunuyor. Çalışmanın amacı, cihazlar üzerinde kullanılan grafik sembollerin kullanıcılar, üreticiler ve tasarımcılar açısından öneminin araştırılması ve klimaların uzaktan kumandaları üzerinde bulunan sembollerin incelenmesidir. Bu amaçla, Türkiye'de satışı yapılan 14 klima markası, sembol farklılıkları gözetilerek kasti örnekleme yöntemiyle seçilmiş, ve klimaların uzaktan kumandaları üzerindeki semboller karşılaştırmalı olarak incelenmiştir. Sonuçta, bu alanda kullanılan evrensel bir sembol dilinin olmadığı görülmüş, mevcut tasarım sorunları tespit edilerek çözüm önerileri sunulmuştur.

\section{VISUAL LANGUAGE OF DEVICES: GRAPHICAL SYMBOLS ON THE REMOTE CONTROLS OF AIR CONDITIONERS}

\footnotetext{
Abstract

Nowadays, lots of devices have become a part of everyday life and most of them have graphical symbols on their buttons or displays. The aim of this study is to examine the importance of these symbols, for users, manufacturers, designers, and to investigate the symbols on the remote controls of air conditioners. To this end, 14 air conditioners are selected among the brands sold in Turkey, through the purposive sampling method. Various symbols are investigated from a comparative perspective. It is illustrated that there is not a universal symbol language and recommendations for the design problems are presented.
}

Anahtar Kelimeler

Grafik Sembol

ikon

Görsel İletişim

Arayüz Tasarım

Kullanılabilirlik

\section{Keywords}

Graphical Symbol

Icon

Visual Communication Interface Design

Usability 


\section{Giriş}

Günümüzde küreselleşmeye ve teknolojik gelişmelere bağlı olarak görsel iletişime duyulan intiyaç da artmıştır. Artık, çok işlevli ve karmaşık arayüzlere sahip birçok cihaz günlük hayatımızın ayrılmaz birer parçası haline gelmiş durumdadır. Bu cihazlarının çoğunun ekran ve tuşları yazılı açıklamaların sığamayacağı kadar küçük boyutlarda olduğundan, tasarımcılar arayüzlerde metin yerine semboller kullanmak zorunda kalmaktadır.

Sembol kullanımı, tasarımcılar için olduğu kadar, üreticiler açısından da bir zorunluk haline gelmiştir. Ürünlerini dünya çapında dağıtan firmalar, cihazların arayüzlerini ve kullanım talimatlarını, ürünün ihraç edildiği her ülke için ayrıca tercüme ettirmek yerine sembol kullanmayı tercih etmektedir. Dil sınırlamalarını ortadan kaldıran semboller, ürünün küreselleşmesini de kolaylaştırmaktadır.

Yeni sembollere duyulan ihtiyaç sürekli artarken, birbiri ile çelişen, benzeşen ve akıl karısıklığına sebep olan semboller ile sıkça karşılaşılmakta ve bu semboller, cihazların kullanımında güçlüklere sebep olmaktadır. Dolayısıyla, grafik sembollerin tasarımı daha önce hiç olmadığı kadar önemli hale gelmiştir.

\section{Grafik Semboller}

Genel anlamı ile, bir sembol, başka bir şeyi göstermek için kullanılan betimleyici grafik karakter ya da şekildir. Belli bir mesajı iletmek amacıyla; gösteren ile gösterilen arasında bir bağ kurar. Grafik semboller ile ilgili uluslararası standartlarda iki ana kavram kullanılmaktadır: "grafik sembol" ve "ikon". Bu kavramlar Uluslararası Standart Organizasyonu (ISO) tarafından aşağıdaki şekilde tanımlanır:

"Grafik Sembol1: Dilden bağımsız olarak bilgi iletmekte kullanılan, belirli bir anlamı olan görsel olarak algılanabilir şekil.

ikon: Ekran ve monitör üzerinde kullanılan grafik sembol." (ISO, 2004)

1. Metin içinde 'grafik sembol' yerine 'sembol' kullanılacaktır. 
Görsel iletişimin en katıksız hali olan semboller, kelimelerden çok daha eskidir. İyi tasarlanmış, belirgin sembollerin kelimeler karşııında önemli üstünlükleri vardır. Bunlardan en önemlisi, dünya üzerinde konuşulan 5800 dil ve lehçenin sebep olduğu kültürel sınırların aşıımasına yardımcı olabilmeleridir. Ayrıca, öğrenilmeleri hızlı ve kolaydır. Daha küçük alanlara sığabildikleri için, görme güçlüğü çeken kişilerin ihtiyaçlarına daha uygundur. Anlamları yazıya oranla daha hızlı kavranabildiğinden güvenlik işaretlerinde özellikle semboller kullanılmaktadır. Tüm bu avantajları sebebi ile grafik sembollerin, tüketici ürünleri ve profesyonel ürünler üzerinde kullanımı gittikçe yaygınlaşmaktadır.

Ancak, grafik sembollerin yukarıda bahsedilen avantajları yalnızca sembolün temsil ettiği kavramın iyi anlaşıması ve en az detayla, somut bir biçimde temsil edilmesi ile mümkün olmaktadır. "Güvenli, etkili ve konforlu kullanım için sembollerin mümkün olduğunca yüksek tanınabilirlikte olması gerekir." (Dumitrescu, 2011:43)

Cihazlar üzerinde çok farklı amaçlarla sembol kullanılabilmektedir. Semboller farklı türde bilgileri iletebilirler. Başlıca kullanım amaçları şu şekilde listelenebilir:

- Ürünün bir bölümünü tanımlamak için,

- Bir fonksiyonu başlatan butonu tanımlamak için,

- Cihazın işleyiş sürecini belirtmek için,

- Ürünün kullanım talimatlarını göstermek için. (Brigham, 2001:116)

"Genelde, kullanıcının anadilinde yazılmıs, fonksiyonu tanımlayan bir metnin, bir grafik sembolden daha anlaşılır ve güvenilir olduğu bilinmektedir." (Feng,2008:1) Buna karşılık, "basit, kolay ayırt edilen biçim ve renkler, ya da ikisinin kombinasyonları, yazılı kelimeden çok daha hızlı biçimde beyinde anlamlandırılır. Acil durumlarda ya da panik halindeyken, milisaniyelik tepki süreleri bir insanın parmağını, kolunu, bacağını hatta hayatını kurtarabilir." (Dreyfuss, 1984:20) Dolayısıyla, eğer yeterince alan varsa, metin ve sembolleri birarada kullanmak en iyisidir. Ancak daha önce belirtildiği gibi, günümüzde cihazların ekran ve kumanda boyutları küçüldüğünden sembol ve yazının birlikte kullanımı çoğu zaman mümkün olamamakta, dolayısıyla sembollerin anlamlarının kolay anlaşılabilir olmasına her zamankinden daha fazla intiyaç duyulmaktadır. 
Sembolün anlamı, her kullanıcının kendi kullanım amacına ve koşuluna bağlı olarak değişebilir. "Görsel bilginin işlenmesi, Kullanıcı bakış açısı ile, sembolün saptanması, tanımlanması, duyulara ve geçmiş bilgilere dayalı olarak mesajının anlaşılması olarak tanımlanabilir. Sembolü anlamlandırma süreçlerinden saptama, doğrudan duyusal becerilere bağlı iken; tanımlama ve anlama, geçmiş deneyimlere ve hatırlanan bilgilere bağlıdır." (Bruyas, 1998:408)

Dreyfus grafik sembolleri üç farklı tür olarak tanımlar:

1. Betimleyici Semboller: İmge temellidirler. "Mümkün olduğunca bu tür sembollerin kullanımına çalışılmalıdır. Çünkü anlaşılmaları kültürel bağlama daha az bağımlıdır." (Korpi, 2010: 358) Grafik betimlemenin, nesne ile olan benzerliğini en üst seviyeye çıkarabilmek ve bir başka nesne ile karıştırılmasını önlemek için, tasarımda nesnenin karakteristik öğeleri kullanılmalı, benzer başka nesnelerin özellikleri göz önünde bulundurularak bunlardan uzak durulmalıdır.

2. Soyut Semboller: Kavram temellidirler. Mesaj, temel grafik öğelere indirgenir. "Bu sembollerin bazıları ilk başlarda betimleyici semboller olarak ortaya çıkmışsa da zaman içinde tasarımları yalınlaşmış ve sonunda sembolik işaretlere dönüşmüşlerdir." (Dreyfuss, 1984:20) Soyut semboller, anlamları hakkında önceden bilgi sahibi olmayan kişilere bir şey hatırlatmazlar.

3. "Keyfi Semboller: Öğrenme gerektiren, icat edilmiş sembollerdir." (Dreyfuss, 1984:20) (örneğin: Radyasyon sembolü.)

Ancak her durumda, kültürel altyapı, kişinin bir sembolü anlamlandırmasına etki edebilir. Kültürden bağımsız semboller tasarlamak zordur çünkü bireylerin karmaşık kültürel altyapıları sembolün yorumunu bir çok şekilde etkiler. Bilgi kodlama sistemlerindeki eğilimler, kavramsal modellerdeki tanımlar ve estetik yargılardaki değerler, kültürel etkiler olarak kabul edilir. Bunların yanısıra"kullanıcıların değerleri, yaş, cinsiyet, görsel okur yazarlık gibi kültürel özellik ve davranışları, sembollerde sunulan bilginin yorumunu ve hatta kabulünü etkiler. Bu nedenle, farklı kullanıcılar aynı kavram hakkında farklı yorum yapabilirler." (Spinillo, 2012: 3401) 
Tüm bu unsurlar göz önüne alındığında, sembol tasarımında kullanıcı odaklı bir yaklaşıma sahip uzmanlara intiyaç duyulduğu açıktır. Ancak Perry'in (2003:8) tespit ettiği gibi, tüketici ürünleri üzerindeki bazı semboller, ürünün kendisi hakkında uzman olup, gerçekte sembol araştırması ve tasarımı konusunda bilgisi olmayan az sayıda kişi tarafından üretilmektedir. Bunun sonucu da, çoğu zaman, farklı anlam ve yorumlara sebebiyet veren, kötü tasarlanmış semboller olmaktadır.

"Tasarımcılar hedef kitle ve onların intiyaçları hakkında dikkatlice düşünmelidir. Hedef kitle, çocuklar, yaşılıar gibi tek bir kesim olabileceği gibi, halkın çeşitli fiziksel ve zihinsel becerilere sahip farklı kesimlerini de kapsayabilir" (Perry, 2003:10). Ayrıca, uluslararası alanda kullanılacak semboller farklı kültürler tarafından anlaşıır olmalıdır. Oysa çoğu zaman bu sembolleri yaratan tasarımcılar genel eğilimleri göz ardı edemez ve kültürün etkisi altında kalırlar. "Tasarımcı tersini yaptığını düşünse de gerçekte, piktografik sembollerin evrensel düzeyde anlaşılabilir olduğunu varsayarak ve imgeye dayalı olmayan, soyut veya göreceli tasarım fikirlerini uygulayarak kültüre bağımlı semboller yaratmaktadır." (Korpi, 2010:355)

Standart sembollere sahip olmak bu tür karışıklıkların önüne geçebilir. Uluslararası kabul görmüş ve dünya genelinde herkesin anlayabileceği bir dizi sembolün tasarlanması gerekmektedir. Grafik sembollere ilişkin bu tür standartların hazırlanmasından iki uluslararası komite sorumludur: Uluslararası Standardizasyon Kurumu'nun teknik komitesi (ISO - International Organization for Standardization) ve Uluslararası Elektroteknik Komite (IEC - International Electrotechnical Commission). Bu kurumlar standart sembollerin yaratılması ve sembollerin etkililiklerinin sağlanması için gerekli prosedürleri belirler.

Cihazlar üzerindeki grafik sembollerin kullanımı ile ilgili temel yayın ISO 7000'dir. ISO Teknik Komite tüketici ürünleri üzerinde kullanılacak sembolleri geliştirir ve sembollerin yaratılması sırasında uyulacak kuralları belirler. ISO 7000 (2004) varolan standart sembolleri kataloglar. ISO-IEC Guide 74 ise yeni bir sembole gereksinim olduğunda, tüketicilerin ihtiyaçlarının kesin biçimde saptandığından emin olabilmek amacıyla hazırlanmıştır.

Yeni cihazların geliştirilmesi ile birlikte sürekli olarak yeni sembol intiyacı doğmaktadır. Ancak, yeni grafik sembollerin ortaya çıkması 
kullanıcıları tekrar tekrar öğrenmeye zorlar. Bu nedenle uygun standart semboller bulunabildiği sürece tamamen yeni semboller yaratmaktan kaçınılmalıdır. Bu yüzden, yeni bir sembol tasarlarken ilk adım her zaman, aynı ya da benzer anlamdaki standart sembollerin araştırılmasıdır. ISO 7000 ve IEC 60417, uygun sembolün bulunabileceği uluslararası standart sembollerin derlendiği kataloglardır.

Sembollerin tasarımı, ürünün kullanılabilirliğini önemli ölçüde etkiler. "Kötü tasarlanan semboller ve aynı anlama gelen farklı semboller kullanıcıların aklını karıştıır. Semboller, ilgili uluslararası standartlarca belirlenen prosedürlere uygun olarak tasarlanmadığı ve geliştirilmediği sürece bu tür sorunlar, kitlesel seyahat ve küresel ticaret çağında daha da yaygın hale gelecektir." (Karwoski, 2011: 129)

Kullanılabilirlik için sembollerin iyi araştırllıp tasarlanmış olması yeterli değildir. Aynı zamanda doğru biçimde uygulanmaları da gerekir. "Örneğin, arka plan rengi ile işaretin üzerinde bulunduğu arka plan, sembolün yeterince öne çıkamamasına ve anlaşılamamasına neden olabilir. Kötü ışıklandırma da aynı etkiyi yaratır. İşaretin boyutları, yerleştirildiği yer ve dayanıklılığı da bu bağlamda dikkatlice değerlendirilmesi gereken etmenlerdir." (Perry, 2003: 11)

Yeni sembollerin yaratııırken, tasarım sürecinde, aşağıdaki unsurların göz önünde bulundurulması büyük önem taşır:

- Sembolün anlamı kolaylıkla anlaşılabilmelidir. Benzer sembollerle karışmayacak biçimde ayırt edilebilir olmalıdır. Açıklanma gerektirmemeli ya da en azından hatırlanması kolay olmalıdır.

- Görünürlük için sembol tasarlanırken çözünürlüğü hesaba katılmalıdır.

- Ortalama görüş mesafesine uygun büyüklükte olmalıdır.

- Kolay okunabilmelidir.

- Aynı uygulama alanı üzerinde bulunan semboller birbiri ile tutarlı bir görsel dile sahip olmalıdır.

- Aynı türdeki ürünler için tasarlanan semboller (sembol aileleri) aynı oranda soyutlanmış olmalıdır.

- Aynı ekran üzerinde bulunan farklı semboller görsel olarak dengelenmelidir.

- Sembollerin iki boyutlu çizimlerden oluşması tercih edilmelidir. Perspektif görünüşler algılamayı güçleştirecektir. 
- Yeterli alan olduğu takdirde, önemli semboller yazııı tanımlar ile birlikte kullanılmalıdır.

Bir dönem dünya genelinde yaygın olarak kullanılan kasetçalar gibi bazı cihazların üzerindeki semboller, yalnız geometrik şekillerden oluşmalarına karşın günümüzde birçok kişi tarafından kolaylıkla tanınmaktadır. Sembollerin kullanımı yaygınlaştıkça bilinirlikleri daha da artacaktır. Oysa sürekli olarak yeni cihazlar yaratılmakta ve herbiri için işlevlerine uygun yeni sembollere ihtiyaç duyulmaktadır.

\section{Klimaların Uzaktan Kumandaları Üzerindeki Grafik Semboller}

Semboller, ürününün fonksiyonlarının anlaşılıp, çalıştırabilmesi için kullanıııya gerekli ipuçlarını sağlamalıdır. Bu durum, kullanıcı ürün ile ilk kez karşılaşıyorsa, ya da nasıl çalışııııdığını unuttuysa özellikle önemlidir. İnternet forumlarında birçok kullanıcı, kullanım kılavuzunu kaybettiği için klimasını kullanmakta zorluk yaşadığını belirtmektedir. Kullanım kılavuzuna intiyaç duyuluyor olması, bu ürünlerin kullanımını önemli bir zihinsel çaba gerektirdiğini ortaya koyar. Farklı markaların, benzer fonksiyonlar için birbirinden farklı semboller kullanıyor olması da durumu güçleştirmektedir. Foster'ın belirttiği gibi; "Birçok ülkede birçok tasarımc basit mesajlar iletmek için semboller yaratmıştır. Bu grafik sembol tutkusu, aynı anlama gelen farklı semboller nedeniyle olası akıl karışıkıklarına zemin hazırlamıştır." (Foster, 2001: 12).

"Fonksiyonlar ve çalışma modları buton sayısından fazla olduğunda zorlukların çıkması muhtemeldir. Tasarım göreceli, tuhaf ve karmaşık bir hal alır." (Norman, 2002: 22) Her ne kadar klimaların fonksiyonları sınırlı sayıda olsa da, uzaktan kumandaları üzerinde, günlük hayatımızdaki bir çok cihaza göre daha fazla sembol bulunmaktadır. Bir klimayı kullanırken, sadece uzaktan kumandası üstünde bulunan küçük bir ekran ve birkaç buton ile etkileşime geçeriz. Bu nedenle, kumandaların tasarımları kullanılabilirliği doğrudan etkilemektedir.

Kullanılabilirlik kısaca, ürün ve sistemlerin öğrenilmesi ve kullanımasının kolaylığı, kullanıı intiyaç ve gereksinimlerinin tespiti ile ilgilidir. Kolay kullanılan ürünler hayatımızı kolaylaştııı, yaşam kalitemizi artırır. Benzer şekilde,ISO 9241-11 kullanılabilirliği: "Belirli kullanıııların belirlenmiş hedeflerini, özel bir ortamda etkin, verimli, rahat ve kabul edilebilir bir yoldan gerçekleştirebilme düzeyi" olarak tanımlamıştır. 
“Birden fazla ülkedeki kullanıcıları hedefleyen üretici ve tasarımcılar kumandaları daha az kelime, daha fazla evrensel sembol içerecek biçimde değiştirmişlerdir. Bu sayede, kumandalar üzerinde bulunan semboller görsel iletişimin başta gelen örnekleri haline gelmiştir." (Racine, 2002: 19) Bu genel tespit, dünyanın her yerine ihraç edilen klimalar için de geçerlidir. Dolayısıyla, klimaların arayüzlerindeki sembollerin farklı kültürler tarafından anlaşılabilir olması son derece önemlidir.

\section{Amaç Ve Yöntem}

Çalışmanın amacı, farkı markalara ait klimaların uzaktan kumandaları üzerinde bulunan klimaların temel fonksiyonlarını belirten sembollerin karşış̧ı̧ırmalı olarak incelenmesi ve tasarım sorunlarının belirlenmesidir.

Çalışma, duvar tipi klimaların beş temel fonksiyonu için kullanılan semboller ile sınırlandırılmıştır. Sembol verileri, internet üzerinden erişilebilen kullanım kılavuzlarından derlenmiştir. Bazı markaların kamu kullanımına açık kullanım kılavuzlarının olmaması çalışmayı sınırlamıştır.

Çalışmada kasti örnekleme tekniği kullanılmışır. Türkiye'de satışı yapılan klima markaları arasından, sembol çeşitliliği gözetilerek seçilen 14 marka örneklemi oluşturulmaktadır. Uzaktan kumandaları üzerinde sembol bulunmayan markalar incelemeye dahil edilmemiştir. Araştırma verileri ışı̆̆ında, sembol tasarımları, temsil ettikleri fonksiyon türüne göre karşılaştırmalı olarak değerlendirilmiştir.

\section{Bulgular}

Klimaların beş temel fonksiyonu bulunmaktadır: Otomatik, ısıtma, soğutma, nem alma ve fan (havalandırma). Buna karşılık, uzaktan kumanda üzerinde bu fonksiyonlar arasından seçim yapılmasına olanak sağlayan tek bir 'mod' tuşu bulunur ve kullanıc hangi mod'un aktif olduğunu sadece ekranda beliren sembole bakarak tespit edebilir.

Otomatik konumdayken klima oda sıcaklığını algılar ve fonksiyonlar arasında otomatik geçiş yapar. En fazla çeşitlilik bu özel fonksiyon için kullanılan sembollerde görülmektedir. Neredeyse her marka farklı bir otomatik çalısma modu sembolü tercih etmiştir. Bu sembollerden 
bazılarında otomatik kelimesinin İngilizce kısaltması olan 'Auto'dan yola çıkılarak, majiskül 'A' harfi kullanılmıştır. Bu sembol dilden bağımsız değildir ve mesajın farklı kültürlerden kullanııılara iletilmesinde sorun yaratabilir. Mitsubishi ve Sharp markaları, otomatik seçeneği için, ISO 7000'de tanımlanan standart sembolü kullanmıştır. Baymak'ın kullandığı sembol de bu standarttan yola çıkılarak hazırlanmıştır. Bununla beraber bu sembol, "geri dönüşüm" sembolüne fazlaca benzemektedir. Birbirini takip eden iki okun kullanıldığı semboller farklı markalar tarafından kullanılmışıı. Beko, Delonghi ve Samsung ise otomatik fonksiyon seçeneği için betimleyici bir sembol kullanmayı tercih etmiş ve insan zekasına gönderme yaparak, insan profilini sembolleştirmiştir. (Tablo 1)

\begin{tabular}{|c|c|c|c|c|c|}
\hline Marka & $\begin{array}{l}\text { 善 } \\
\text { 言 }\end{array}$ & $\frac{\underline{\underline{\underline{E}}}}{\underline{\underline{\underline{m}}}}$ & 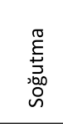 & 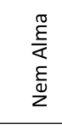 & 胥 \\
\hline Alarko Carrier & $A$ & 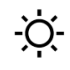 & 㖼 & 0 & (8) \\
\hline Baymak & $\Delta$ & 淡 & 类 & 0 & (2) \\
\hline Beko / Arçelik & $\mathbf{A}$ & 棕- & 米 & 0 & + \\
\hline Daewoo & AUTO & 60 & $z_{x}^{*}$ & 80 & $82 x$ \\
\hline Daikin & {$[\underline{\underline{A}}$} & 㓥 & 櫒 & 80 & 8 \\
\hline Delonghi & (¿) & 滈 & * & 0 & 85 \\
\hline Demirdöküm & Auto & 棌 & 莎 & 00 & S \\
\hline Hitachi & 0 & (2) & 菻 & 0 & $x$ \\
\hline Mitsubishi & (d) & :":ְל: & 米 & 0 & $\equiv$ \\
\hline Profilo & מד & 棕 & 楛 & 8 & 올 \\
\hline Samsung & \{Avto & 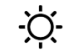 & E & 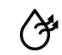 & 86 \\
\hline Sanyo & (A) & - & 88 & 0 & 85 \\
\hline Sharp & (2) & 㴔 & 米 & WII & موك \\
\hline Toshiba & A & -:- & 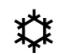 & $\Delta$ & (8) \\
\hline
\end{tabular}

Tablo 1: Farklı markalara ait klimaların uzaktan kumandaları üzerinde bulunan fonksiyon sembolleri. 
Klimaların ısıtma fonksiyonu için neredeyse her zaman 'güneş' sembolü kullanılır. Oysa bu durum, farklı alanlarda kullanılan güneş sembollerinin alışılagelmiş anlamları ile çelişmektedir.

Güneş sembolü, fotoğraf makinelerinde gün ışığı modunu temsil eder. Havanın güneşli olması durumunda bu modun tercih edilmesi gerekir. Güneş ve kar sembolleri günlük hayatımızda en sık olarak, hava durumlarında karşımıza çıkar ve güneş, havanın sıcak ve güneşli olduğunu belirtir, yaz mevsimi ile ilişkilendirilir. Bunlara karşılık, klimalar üzerinde kullanılan güneş sembolünün yaz mevsimi ile ya da havanın güneşli olmasıyla bir ilgisi yoktur. Soğuk havalarda kullanılacak olan ısıtma fonksiyonu güneş sembolü ile anlatılmaktadır ve bu durum birçok klima kullanıcısında akıl karışıkığına neden olmaktadır. Daewoo, birçok markanın aksine, ısıtma fonksiyonu için, güneş yerine alev sembolü kullanmıştır. Ama grafik tasarımı nedeniyle tanınması ve dolayısıyla anlaşılması oldukça güçtür. Diğer taraftan, Hitachi sadece belirli kültürel altyapıya sahip kişilerin anlayabileceği, oldukça soyut bir güneş sembolü kullanmıştır. (Tablo 1)

Soğutma foksiyonu için, farklı çeşitlemeler olsa da, markaların tümü, ISO'nun bu amaç için hazırladığı 'kar tanesi' sembolünü kullanmıştır. Yine de Delonghi, Daewoo and Sanyo'nun sembollerinin oldukça zor algılandığı görülmektedir. (Tablo 1)

Klimaların nem alma fonksiyonu havadaki nemi alır. Bu fonksiyon genelde 'su damlası' sembolü ile gösterilir. Ama, su damlası üzerinde, olumsuzluk belirten herhangi işaret bulunmadığından, birçok kullanıcı, klimanın bu özelliğinin odayı nemlendirdiğini düşünmektedir. Bu nedenle, kurutma etkisini görsel olarak anlatabilmesi için, su damlası sembolünün üzerine çapraz bir çizgi çekilmesi faydalı olabilir. Bu açıdan, mesajı doğru ileten, en kullanıcı dostu sembol Samsung'da bulunmaktadır. Daewoo klimada kullanılan nem alma sembolü diğerlerinden oldukça farklıdır; su damlasının yanına çizilen Pacman² sembolü, nemin yok edilmesi mesajını esprili bir yolla iletir. (Tablo 1)

2. Pacman: 1980 yılında Japonya'da tasarlanan ve kült haline gelen bir bilgisayar oyunu. Pacman karakterinin amacı ekran üzerindeki tüm noktaları yemektir. 
Fan modu, klimaların kumandalarında genellikle pervane simgesi ile gösterilir. Yine de, grafik tasarımlar açısından markalar arasında büyük farklar göze çarpmaktadır. Bazı klima markaları, sembolde gereksiz ayrıntılara yer verirken, bazıları çok keskin hatlı formlar kullanarak pervane biçiminin algılanmasını güçleştirmiştir. Mitsubishi hava dolaşımını ifade etmek adına, dalgalı üç ok işareti kullanmışır. Ama okların yönü mesaj iletilmesinde sorun yaratabilir. Birçok dilde yazım yönünün soldan sağa olduğu göz önünde bulundurulduğunda, sola dönük olan bu okların, havanın klimanın içine doğru çekildiği algısını yaratacağı söylenebilir. (Tablo 1)

Anlaşılabilirliklerini artırmak için, semboller arasında görsel tutarlılık sağlanmalıdır. Goodwin: "İnsanlar hem içerik, hem de bağlamdan anlam çıkarır. Tıpkı bir cümle içinde geçen bilmediğimiz bir kelimede olduğu gibi, bir sembolün anlamı tek başına yeterince açık olmayabilir ama etrafındaki semboller ile anlam kazanır." demiştir. (Goodwin, 2009: 583) Başka bir deyişle, kullanıcılar tanımadıkları bir sembolün anlamını çözmek için diğer sembollere bakarlar. Anlam karmaşasına düştüğünde kullanıcı, sembol-anlam ilişkileri arasında tutarlı bir örüntü olduğunu varsayar ve mantık yürütür. Bu varsayım, tanımadığı sembolün anlamını çıkarmak için gerekli olan temeli kullanıcıya sağlar. Bu bilgiler ışığında, klima kumandaları üzerinde kullanılan sembolleri değerlendirecek olursak; nem alma fonksiyonundan yola çıkarak, damla sembolü ile nem azaltılıyorsa, aynı mantıkla güneş sembolü seçildiğinde oda ısısııın düşürüleceği sonucuna varılabilir. Sonuç olarak, farklı fonksiyonlar için kullanılan sembollerin tutarsızlığının sembollerin öğrenilmesini ve cihazın kullanımını güçleştirdiği söylenebilir.

\section{Öneriler}

1. Klimaların uzaktan kumandaları üzerinde kullanılan sembollerin farklılık gösterdiği ve evrensel bir görsel anlatım dilinin olmadığı görülmüştür. Aynı türdeki cihazlarda benzer sembollerin yer alması cihazın öğrenilmesini ve kullanımını kolaylaştıracaktır.

2. Farklı ülkelerdeki kullanııılar dikkate alınarak, dilden bağımsız semboller yaratı Imasına çalışılmalıdır. Herhangi bir kelimenin baş harfi ile oluşturulan semboller, bu dili bilmeyen kişiler için tamamen anlaşılmaz olmaktadır. 
3. Fonksiyonları (eylemleri) göstermek amacıyla durum belirten bir sembol seçilmemesine dikkat edilmelidir. Örneğin; "Isıtma" fonksiyonu için "sıcaklık" anlamına gelen bir sembol kullanılmamalıdır.

4. Nem alma fonksiyonunun "nem" sembolü ile gösterilmesinde olduğu gibi, sembolün temsil ettiği fonksiyon ile çelişmemesine dikkat edilmelidir. Sembole eklenecek grafik şekiller ile bu durum önlenebilir.

5. Etkili bir görsel iletişim için, tasarımcılar sembollerin net biçimde anlaşılabilir olmasına, kolay öğrenilip hatırlanabilecek biçimde tasarlanmalarına özen göstermelidir. Sembolleri oluşturan grafik ögeler, soyut biçimler yerine, detaylarından arındırımış, imge temelli, betimleyici formlar olmalıdır.

\section{Sonuç}

Sembollerin kullanımının yaygınlaşmasının başlıca nedenleri; kültürden ve konuşulan dilden bağımsız olmaları, yazılı açıklamalara göre daha az yer kaplamalarıdır. Küresel boyutta ticaret ve yolculukların yaygınlaşı̆̆ı çağımızda, evrensel bir görsel dile duyulan intiyaç sembol kullanımının artmasına neden olmuştur.

Tasarımcılar sembollerini tasarlayacakları cihaz ile aynı türdeki cihazları incelenmeli, sembollerin birbirine yakın olmasına çalısmalıdır. Tamamen farkı bir tasarım kullanıcıların anlamalarını zorlaştırabilir. Herkes tarafından bilinen, sıkça kullanılan bazı sembolleri kullanmaya devam etmek faydalı olacaktır. Bu tür tasarım alışkanlıkları ya da standartlar kullanıcıların işini kolaylaştııır, yeni bir dizi sembolü öğrenmek zorunda kalmadan, cihazı kullanmaya hemen başlayabilirler. Yine de standartlara uymak her zaman iyi sonuç vermeyebilir. Standartlara uygun sembollerin bile etkinliğinin test edilmesi ve gerekiyorsa değişikliklerin yapılması zorunludur.

Yeni semboller tasarlanırken, kullanıcıların farklı yaş gruplarına mensup, farklı zihinsel ve fiziksel becerilere sahip kişiler olabileceği göz önünde bulundurulmalıdır. Kullanıııar görüşleri dikkate alınarak, tasarım sürecine dahil edilmeleri sağlanmalıdır. Böylece, ürünlerin kullanılabilirliği artırılıp kültür ve dilden bağımsız evrensel bir görsel dilin yaratılması mümkün olabilir. 


\section{Kaynakça}

Brigham, Fred, "Graphical symbols for consumer products in an international context" Information Design Journal, 10(2), 2001: 115123.

Bruyas Marie, Le Breton Blandine, Pauzie Annie, "Ergonomic guidelines for the design of pictorial information", International Journal of Industrial Ergonomics, 21, 1998: 407-413.

Dreyfuss, Henry, Symbol Sourcebook: An Authoritative Guide to International Graphic Symbols, John Wiley\& Sons, 1984.

Dumitrescu, Andrei, "Recognition Of Graphic Symbols On Product Interface" Academic Journal Of Manufacturing Engineering, 9 (1), 2011: 43-48.

Feng, Xing, "A Pilot Study Evaluating the Comprehensibility of Graphical Symbol: Potential Impact on Aging Population and Its Implication", RESNA Annual Conference Proceedings, 2008. (erişim) http://web.resna.org/conference/proceedings/2008/JEA/Feng.html, Mayıs 2013.

Foster, Jeremy J., "Graphical Symbols: Test methods for judged comprehensibility and for comprehension", ISO Bulletin, Aralık, 2001: 11-13.

Goodwin, Kim, Designing for The Digital Age: How to Create Human Centered Products and Services, John Wiley\& Sons, 2009.

International Organization for Standardization, ISO 7000 Graphical symbols for use on equipment, Geneva, 2004.

Karwoski Waldemar, Soares Marcelo M., Stanton Neville A.(Ed.), Human Factors and Ergonomics in Consumer Product Design: Methods and Techniques, Taylor\&Francis Group, 2011.

Korpi Jari, Ahonen-Rainio Paula, "Cultural Constraints in the Design of Pictographic Symbols", The Cartographic Journal, 47(4), 2010: 351-359. 
Norman, Donald A., The Design of Everyday Things, New York Basic Books, 2002.

Perry, John, "Graphical symbols to address consumer needs" ISO Bulletin, Mart, 2003: 8-11.

Racine, Ned, Visual Communication. Learning Express LLC., 2002.

Spinillo, Carla G., "Graphic and cultural aspects of pictograms: an information ergonomics viewpoint" Work, 41, IOS Press, 2012: 33983403.

\section{Sembol Kaynakları}

Alarko Carrier, 1110250107-(2).indd. 27, 2007, (erişim) http://www.alarko carrier.com.tr/ Urun/ Kulkilavuzu/CarrierGold_KK.pdf, Mayıs 2013.

Baymak, Duvar tipi split klima montaj ve kullanma kılavuzu 12/18 CHS premium, 2012, (erişim) http://www.baymak.com.tr/UserFiles/AttachmentFiles/Klima/ID_3677 _tr_TR2. Montaj\%20ve\%20Kullanma\%20K\% C4\% B1lavuzuBaymak\%20Premiu\%20Duvar\%20Tipi \%20Split\% 20Klima.pdf, Mayıs 2013.

Beko, Klima kullanma kılavuzu 8510/8610/8650/8700/ 8800 D. (erişim) http://klimamvar.com/wp-content/uploads/2012/11/BEKOKULLANMA-KILAVUZU.pdf, Mayıs 2013.

Daewoo, Owner's manual split airconditioning system DSB122L/DSB-122LH, (erişim) http://homeappliance.manualsonline.com/manuals/ mfg/ daewoo_electronics/dsb-122lh.html?idRes=515688, Mayıs 2013.

Daikin, Room air conditioner operation manual FDXS25-35-5060LVMA, http://www.daikin.com.au/sites/default/files/FDXS25-35-5060LVMA.pdf, Mayıs 2013. 
Delonghi, Operating and installation manual one invertor, single split dc inverter and on-off air conditioners and heat pump, 2007, (erişim) http://www.delonghi.com.au/support/ instruction_manuals/DEFS26_im.pdf, Mayıs 2013.

Demirdöküm, Klima montaj ve kullanma kılavuzu A2 09/12/18/24, $\left(\begin{array}{llllll}\mathrm{e} & \mathrm{r} & \mathrm{i} & \mathrm{s} & \mathrm{i} & \mathrm{m}\end{array}\right)$ http://www.demirdokum.com.tr/upload/Kutuphane/141/A2_Duvar_Ti pi.pdf, Mayıs 2013.

Hitachi, Split type air conditioner, model RAS-X18CBT/RACX18CBT, (erişim) http://www.hapm.hitachiasia.com/index/techsupp/OperationManual/RAS_RAC-X18CBT \%28EN\% 29 REV01.pdf, Mayıs 2013.

Mitsubishi, Air conditioner user's manual SRK63ZE-S1/SRK71ZES1, (erişim) http://www.iklimplus.com.tr/pdf/kullanimkilavuzlari/mitsubishi-klima-kullanimkilavuzu.pdf, Mayıs 2013.

Profilo, Klima kullanıcı kılavuzu, uzaktan kumanda ile ilgili açıklamalar P3ZMA 12907/ P3ZMA 18907/ P3ZMI 12907/ P3ZMI 18907, (erişim) http://www.profilo.com.tr/ Files/ Profilo /Tr/tr/Document/p-12907 kumanda.pdf, Mayıs 2013.

Samsung, Split tipi klima kullanma kılavuzu AS09HM3N, (erişim) http://tr.pdf-instructions.com/dref /805796, Mayıs 2013.

Sanyo, Instruction manual split system air conditioner KS0951/KS1251/KS1852, 2002, (erişim) http://us.sanyo.com/dynamic/product/Downloads/oi09KS5109KLS51-10432455. PDF, Mayıs 2013.

Sharp, Kullanma kılavuzu split type room air conditioner AYAP18CE/AY-AP24CE/AH-AP18CE/AH-AP24CE, (erişim) http://www.sharpklimalar.com/images/ kullanim-kilavuzu/ sharpklima-kullanim-kilavuzu.pdf, Mayıs 2013.

Toshiba, Kullanma kılavuzu 1110250101-(3).indd 34, 2007, (erişim) http://www.alarkocarrier.com.tr/Urun/Kulkilavuzu/ToshibaSKV_KK.pdf, Mayıs 2013. 